\title{
Polychlorinated Biphenyls in Fish Species from Guanting Reservoir, Beijing, People's Republic of China
}

\author{
X. T. Wang, Y. Z. Sun, X. H. Li, Z. Z. Yang, X. B. Xu \\ State Key Laboratory of Environmental Chemistry and Ecotoxicology, Research \\ Center for Eco-Environmental Sciences, Chinese Academy of Sciences, \\ Beijing, 100085, People's Republic of China
}

Received: 15 December 2005/Accepted: 8 March 2006

Commercial products of polychlorinated biphenyls (PCBs) are widely used from the $1930 \mathrm{~s}$ to the $1970 \mathrm{~s}$ as fluids in transformers and capacitors, hydraulic fluids, lubricating oils, and as additives in pesticides, inks and paints due to their high chemical stability (Kennish, 1997). PCBs are worldwide ubiquitous anthropogenic environmental pollutants, which are extensively present in various environmental medium such as air, soil, water, sediment and biota (Fowler, 1990; Tanabe ct al., 1994). The amount of PCBs in the global environment has been estimated to be about $3.70 \times 10^{8} \mathrm{~kg}$ and further $7.8 \times 10^{8} \mathrm{~kg}$ were estimated to be still available for utilization or deposited in different ways (Vit, 1992). Accidental leakage and improper disposal of discarded electronic equipments remain potential sources of PCB contamination in China. PCB congeners differ widely in their toxicological and physico-chemical properties according to the numbers and positions of the chlorine atoms in the molecules.

Human exposure to PCBs primarily occurs via low level food contamination (Batters hill, 1994). Fish, meat and diary products are the most important dietary sources of PCBs for humans (Duarte-Davidson and Jones, 1994; ATSDR, 2000). Adverse health effects including skin disorders, neurochemical behavioral changes, immune dysfunction, reproductive and developmental changes, and cancer after accidental exposure have been observed (Carpenter, 1998). Even at low dietary exposurc levels, endocrine disruption and relatively subtle adverse effects on neurobehavioral development have also been observed in humans (Brouwer et al., 1995). Due to the complexity of the PCBs, seven indicator congeners were often used to identify the composition of PCBs. These seven indictor congeners were PCB28, PCB52, PCB101, PCB118, PCB138, PCB153, and PCB180, which were dominantly present in most commercial $\mathrm{PCB}$ products and in environmental samples (Capel et al., 1985; Frignani et al., 2001).

Fish are at the top of the food web of the aquatic ecosystem. Hence fish could be used as bioindicator for water quality and environmental pollution monitoring because they concentrate persistent organic pollutants (POPs) in their tissues directly from water, but also through their diet, thus enabling the assessment of transfer of POPs through the trophic web (Mormede et al., 2003; Fisk et al. 2001; Boon et al., 2002). Data on the presence and distribution of POPs in fish and 


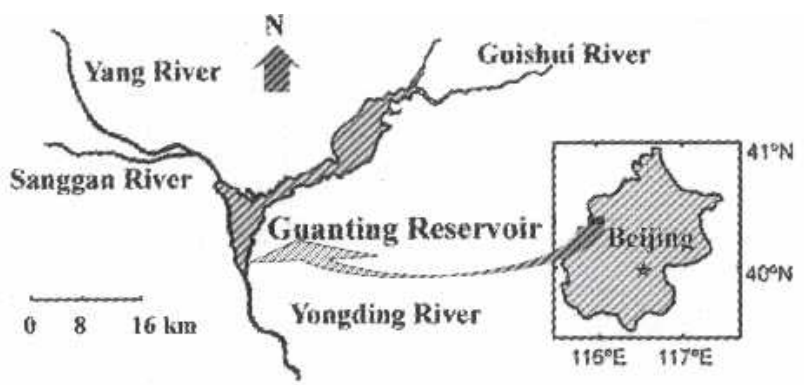

Figure 1. Guanting Reservoir and its location in Beijing

especially edible fish species are therefore important not only for ecological perspective, but also human health. Humans are exposed inadvertently to POPs through numerous sources, of which the consumption of contaminated fish is one of the most important pathways (Fürst, 1993).

The work is a part of a continuous research program on the pollution of Guanting Reservoir and the Yongding River in Beijing. HCHs and DDTs in six kinds of small fish including feral carp, wheat head gudgeon, color gudgeon, Chinese bitterling, silver xenocypris and hemiculter leucisculus were investigated (Sun et al. 2005), but no information is available on the levels of PCBs in different fish species which were readily caught and consumed by the local inhabitants from the reservoir. The objectives of the present study were to investigate the levels and composition of PCB congeners, including the seven indicator PCBs in different fish species collected from Guanting Reservoir, to compare them with reported data from other inland water bodies and to assess their possible sources and to health-based standards for fish consumption.

\section{MATERIALS AND METHODS}

Three composite stock standard solutions of PCBs (PCB Congener Mix \#1 \#3, which totally composed of 102 PCB congeners contained in Aroclors 1242, 1254 and 1260) were obtained from AccuStandard (New Haven, USA). The desired concentration solutions of PCBs were obtained by diluting the standard solutions with iso-octane. Tetrachloro-m-xylene (TCmX) (Chem Service Inc.) was used as surrogate standard. Anhydrous sodium sulfate was purified in a furnace at $600^{\circ} \mathrm{C}$ for $5 \mathrm{hr}$. Silica gel (100-200 mesh) was activated in drying oven at $130^{\circ} \mathrm{C}$ for $16 \mathrm{hr}$ and then deactivated with $3 \%$ water (w/w) after it was cooled down to room temperature in a desiccator. Superclean ENVI-Carb cartridges $(3 \mathrm{~mL}, 250 \mathrm{mg}$ ) (washed with $20 \mathrm{~mL}$ of acetone, toluene and hexane respectively before use) were obtained from Supelco (Bellefone, PA, USA). All solvents used in the study were from Merck (Darmstadt, Germany).

10 fresh fish species including Pond smelt ( Hypomesus olidus), karut croaker (Wak carutta), topmouth culter(Erythroculter ilishaeformis), crucian (Carassius auratus), Yellow catfish (Pelteobagrus fulvidraco), Yellowl Xenocypris (Xenocypris davidi 
Table1. Average length (cm), weight (g) and lipid content $(\%)$ and feeding habits of sampled fish species

\begin{tabular}{|c|c|c|c|c|}
\hline Common name & Length & Weight & Lipid & Main food \\
\hline Pond smelt & 11.5 & 8.4 & 12.39 & Insect larvae, amphipod and isopod, \\
\hline Karut croaker & 11 & 11.32 & 1.75 & Omnivorous \\
\hline Topmouth culter & 22.0 & 64.63 & 5.58 & $\begin{array}{l}\text { Insect, amphipod, isopod and small } \\
\text { fish. }\end{array}$ \\
\hline Crucian & 17.0 & 100.58 & 2.13 & Omnivorous \\
\hline Yellow catfish & 23.5 & 111.9 & 4.99 & $\begin{array}{l}\text { Zooplankton, insect, mollusk and } \\
\text { small fish. }\end{array}$ \\
\hline Yellow Xenocypris & 7.1 & 4.9 & 4.76 & Algae, plant chippings, \\
\hline Large icefish & 19 & 12.42 & 2.20 & Zooplankton, small fish and shrimp. \\
\hline Stone moroko & 8.1 & 4.4 & 11.59 & $\begin{array}{l}\text { Zooplankton, insect, aquatic plant } \\
\text { and algae. }\end{array}$ \\
\hline Chinese false gudgeon & 9.5 & 9.5 & 6.78 & $\begin{array}{l}\text { Insect and larvac, plant chippings, } \\
\text { diatom }\end{array}$ \\
\hline Chinese bitterling & 7.0 & 5.1 & 3.19 & $\begin{array}{l}\text { Algae and advanced plant } \\
\text { chippings. }\end{array}$ \\
\hline
\end{tabular}

Bleeke), Large icefish (Protoslanx hyalocranius), Stone moroko (Pseudorasbora pavra), Chinese false gudgeon (Abbottina rivularis), and Chinese bitterling (Rhodeus sinensis Gunther), which were expressed as GY, BTY, JZL, JY, HSY, HTY, DYY, MSY, BHY and HLP in short, respectively, were collected from local fishermen living in the Guanting prefecture in October 2003. The fishes were wrapped in precleaned aluminum foil and stored at $-20^{\circ} \mathrm{C}$ refrigerator. The information on the length, weight and habitat and feeding preferences for these fish specics is presented in Table 1 .

After thawing, the fish was well homogenized in a tissue homogenizer. Approximately $10 \mathrm{~g}$ (wet weight) of homogenized sample was transferred to a mortar, $30 \mathrm{~g}$ of anhydrous sodium sulfate was added, and then ground until the mixture was free-flowing. Finally, the resulting powder was transferred to a clean beaker, covered with aluminum foil and equilibrated for $16 \mathrm{hr}$ in a desiccator for extraction. The samples were extracted with $200 \mathrm{ml}$ of hexane/acetone $(1: 1, \mathrm{v} / \mathrm{v})$ in hot Soxhlet extraction mode for $24 \mathrm{hr} .1 \mathrm{ml}$ of tetrachloro- $m$-xylene solution at a concentration of $50 \mu \mathrm{g} / \mathrm{L}$ was added before extraction as a surrogate standard. The lipid content of each sample was determined gravimetrically. The remaining extract was dried with anhydrous sodium sulfate and then concentrated in a rotary vacuum evaporator to about $5 \mathrm{~mL}$. Lipid and sulfur removal and clean-up were achieved by using sulfuric acid silica column and mercury, respectively. Organochlorine pesticides were removed using deactivated silica gel $(3 \%)$ chromatography. Co-planar PCBs including Non-ortho PCBs (PCB-77, -81, -126, and -169) and mono-PCBs (PCB-105, -114, -118, -123, -156, -157, -167, and -189) and other PCBs were finally separated into two fractions for each sample using ENVI-Carb cartridge. The fractions were concentrated by a gentle nitrogen steam to $200 \mu \mathrm{L}$ for 
The instrumental analyses were performed by GC6890- $\mu$ ECD (Agilent 6890 series $\Pi$ equipped with a ${ }^{63} \mathrm{Ni}$ electron capture detector). A DB-5 fused silica capillary column $(30 \mathrm{~m} \times 0.25 \mathrm{~mm}$ id, and $0.25 \mu \mathrm{m}$ film thickness) was used. The injection mode was splitless and the purge time was $0.75 \mathrm{~min}$. Nitrogen was used as carrier gas and make-up gas. Detector and injector temperature were $300^{\circ} \mathrm{C}$ and $280^{\circ} \mathrm{C}$, respectively. The GC oven temperature program was carried out as follows: initial temperature $60^{\circ} \mathrm{C}$ held for $1 \mathrm{~min}$, increased to $150^{\circ} \mathrm{C}$ at $15^{\circ} \mathrm{C} / \mathrm{min}$, then to $230^{\circ} \mathrm{C}$ at $6{ }^{\circ} \mathrm{C} / \mathrm{min}$ held for $6 \mathrm{~min}$, finally to $280^{\circ} \mathrm{C}$ and held for $10 \mathrm{~min}$. Peak identification of $\mathrm{PCB}$ congeners were made by comparison of retention time with corresponding standards, and $\mathrm{PCB}$ congeners with higher concentrations in selected samples were confirmed by GC/MS using an Agilient $6890 \mathrm{GC}$ equipped with a model 5973 mass selective detector (MSD) in selected ion mode. Two ions from the molecular cluster were monitored for each analyte. The data were processed by means of a G2070AA GC Chemstation and an external standard method was used for quantitative calculation.

Blank and recovery experiments were run for fish samples including the whole analytical procedure. The target compounds were not detected in the blank run for the entire procedure. For recovery experiments, $\mathrm{PCBs}$ in iso-octane was added to the pure corn oil. The method detection limits (MDLs) of PCB congeners were determined as the concentrations of analytes in a blank sample that gives rise to a peak with a signal-to-noise ratio $(\mathrm{S} / \mathrm{N})$ of 3 . Detection limits of the method ranged from $0.001-0.008 \mathrm{ng} / \mathrm{g}$ for PCB congeners on wet weight base. For every set of 6 samples, a procedural blank and spiked sample consisting of all reagents was run to check for interference and cross-contamination. The spiked recoveries in matrix were in the range of $64.39-108.45 \%$ for PCB congeners, and RSDs ( $n=3$ ) were $7.51-16.29 \%$. In order to monitor the recovery efficiencies of the extraction and cleanup, tetrachloro- $m$-xylene (TCmX) was used as surrogates and the recoveries of surrogate standards spiked in blank, matrix and samples tested were between $75-110 \%$. These results indicated that the analytical protocols used in this study are effective for determination of PCB residues in fish. All residue concentrations below method detection limits were regarded to be equal to zero in calculation of sum, means and so on. All samples were analyzed in duplicate and results reported in the study were means of duplicate analyses, both for qualitative and quantitative analysis. All results were not corrected for recoveries.

\section{RESULTS AND DISCUSSION}

The concentration (shown in Figure 2) of total PCBs and 7 indicator PCBs ranged from 1.09 to $5.19 \mathrm{ng} / \mathrm{g}$ and 0.23 to $0.91 \mathrm{ng} / \mathrm{g}$, with averages of $2.65 \mathrm{ng} / \mathrm{g}$ and 0.47 $\mathrm{ng} / \mathrm{g}$ on a wet weight basis, respectively. The total PCB and indicator PCB concentrations were found in the order: GY $>$ BHY, HTY, MSY $>$ HSY, JY, BTY > HLP, DYY $>$ JZL. It is obvious that GY contained the highest PCB concentration, while the lowest ones were found in JZL and DYY which were only about a fifth of the former. 


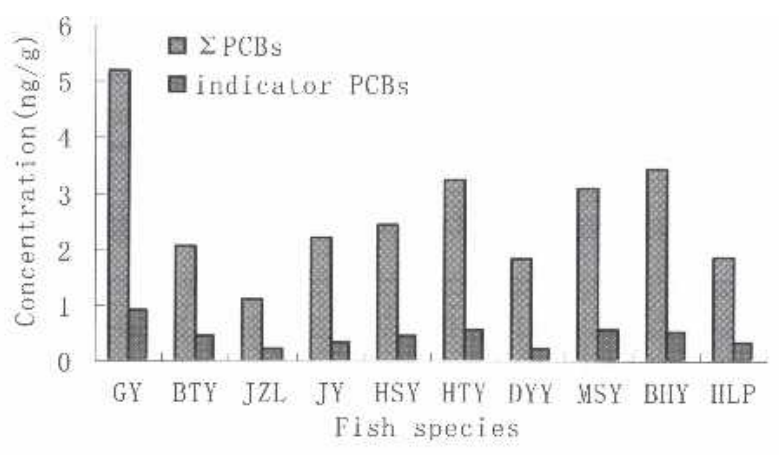

Figure 2. Levels of total PCBs in fish samples from Guanting Reservoir

PCBs are very persistent in the environment and easily bioaccumulate in fish. Many factors influence the uptake and bioaccumulation of PCBs in fish. Bottom feeders easily accumulate more PCBs. Older and larger fish would be expected to have higher concentrations of PCBs. Fast-growing species may have lower PCB concentrations. Fish with more lipid should accumulate higher PCB concentrations than lean fish. The different feeding behavior reflected distribution pattern of PCB congeners in fish, but it is difficult to discriminate the difference among them in this study due to their small sizes and ages. Differences in PCBs concentration in different small fish species inhabited in Guanting Reservoir are mainly associated to different lipid content as well as differences in their feeding habits and probably metabolic differences in PCBs biotransformation..

The lipid contents in each species (Table 1) were significantly different and in the descending order: $\mathrm{GY}>\mathrm{MSY}>\mathrm{BHY}>\mathrm{HLP}>\mathrm{JZL}>\mathrm{HSY}>\mathrm{HTY}>\mathrm{DYY}>\mathrm{JY}>$ BTY. It is obvious that fish with high lipid content accumulated more of PCBs than lean fish. But good linear relation between PCBs and lipid content was not found $\left(r^{2}=0.50\right)$ at the 0.05 level. A significantly positive correlation $(r=0.97)$ was found between total PCBs and indicator PCBs in fish species at the 0.01 level. Therefore, the total PCB concentration in fish samples can be estimated based on indicator PCB content. Here, the linear relation of $\mathrm{PCB}$ concentration with indicator PCB was as follows:

$$
\text { PCBs }=5.5534 * \text { indicators }+0.0432 \quad\left(\mathrm{r}^{2}=0.9412\right)
$$

PCB congeners were detected at low concentrations in all fish samples. A total of 86 PCB congeners were quantified. 35 PCB congeners including PCB 28, 52, 44 , $87,101,118,138,149,153$ and 180 were detected with $100 \%$ detection frequencies in all fish samples. Figure 3 (A) shows the composition profiles of $\mathrm{PCB}$ homologues in 10 fish species. The PCB profiles were similar on the whole for all the fish samples. The dominant PCB homologues in fish samples were tri-, tetra- and pentachlorobiphenyls. The major congeners detected were the lower-chlorinated congeners including $8 / 5,18,28 / 31,44,52,56,66,70 / 76,84,101,110$ and 153 , accounting for $44.79-59.61 \%$ with a mean of $50.70 \%$. The lower-chlorinated 

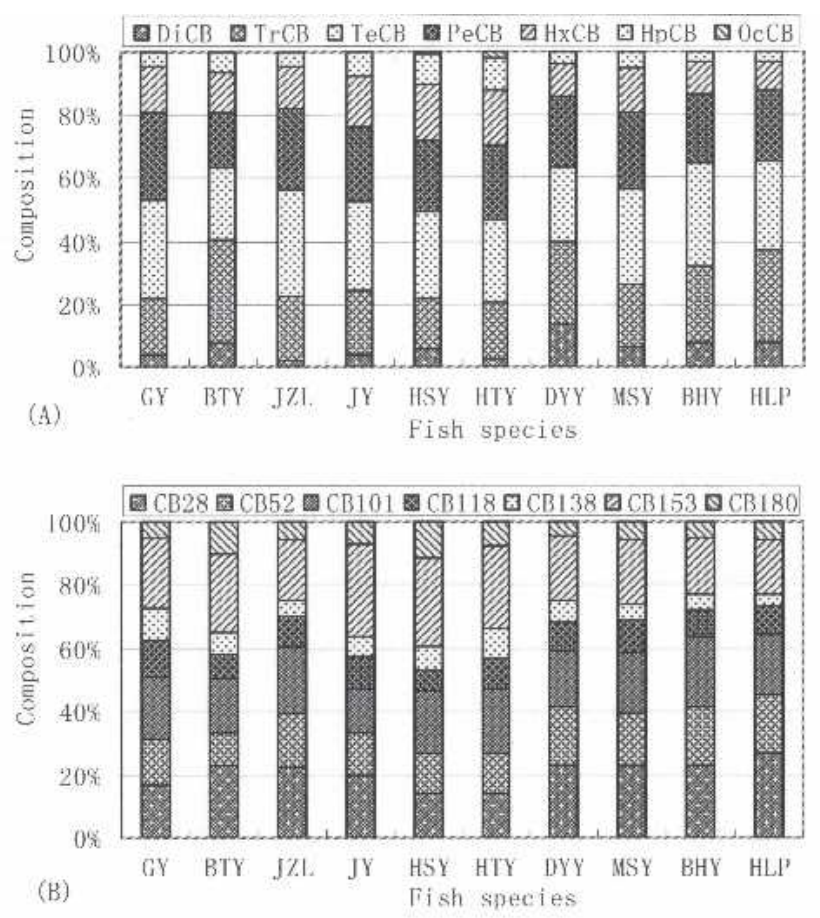

Figure 3. Percent contribution of PCB homologues (A) and indicator PCBs (B) in fish samples from Guanting Reservoir

congeners (di- to penta-CBs) accounted for 70.7 to $87.7 \%$ with a mean of $80.4 \%$ ofthe total PCBs in fish samples in the study. The occurrence of lower-chlorinated congeners and the homologue pattern indicate that atmospheric deposition was probably a major source of PCBs in Guanting Reservoir. The presence of tetrachlorobiphenyls (44 and 52), pentachlorobiphenyls (87, 101 and 118) and hexachlorophenyls $(138,149$ and 153) suggest a contribution from the commercial mixtures Aroclor 1242 and 1254, which have been widely used in electrical equipment in several countries (Montone, et al., 2001).

Figure 3 (B) shows the distribution profiles of the seven indicator PCB congeners in 10 fish species. Seven indicator PCB congeners were found in all fish species, which accounted for $13.46-21.93 \%$, with a mean of $17.89 \%$ of total PCBs analyzed in fish samples. While in Aroclor 1242, 1254 and 1260, the relative contents of indicator PCBs were $11.90,30.41$ and $31.19 \%$, respectively. It is obvious that that the average relative content of 7 indicator congeners in fish samples was higher than that of Aroclor1242, but far lower than that of Aroclor1254 and 1260. The congener 153 showed the highest concentration among indicator congeners and followed in the descending order by the $28,101,52,138$ and 180 , which also indicate atmospheric deposition was main source of PCBs.

The total concentrations of 12 coplanar PCBs were in the range of 0.03 to $0.28 \mathrm{ng} / \mathrm{g}$ 
ww, which accounted for $1.66 \%-4.05 \%$ of the total PCBs. The total mono-ortho PCBs in different fish samples were higher than the total non-ortho PCBs. The predominant coplanar PCB congener was PCB-118, and made up 30.65\%-71.21\% of the total coplanar PCBs. The predominant non-ortho PCB congener was PCB-77, and made up $55.84 \%-84.83 \%$ of the total non-ortho PCBs. In contrast, the levels of PCB-126, PCB-169, PCB-167 and PCB-169, were below their MDLs in most samples. The toxicity equivalents (TEQs) were calculated based on the Humans/mammals toxicity equivalence factors (TEFs) reported by the World Health Organization (WHO) (Van den Berg et al., 1998). The total PCB WHO-TEQs values were $0.003-0.044 \mathrm{pg}$ TEQ/g ww. The contribution of mono-ortho PCBs to total TEQs were between $79.5 \%$ and $97.7 \%$.

The bioconcentration of PCBs in aquatic organisms correlates with the degree of chlorination of biphenyl, the stereochemistry, and lipophilicity (Fox et al., 1994); the congeners with low degree of chlorination are more easily metabolized and eliminated than highly chlorinated ones (McFarland and Clarke, 1989). The occurrence of PCB153, 180, 118, 138, 101, 52 were due to their highly persistent and hydrophobic properties, PCB 153 is considered the most persistent congener and therefore presented higher residue levels in various fish species. While the lower-chlorinated such as PCB 8/5, 18, 28/31, 44, 56, 66, 70/76, 84, and 110 showed higher concentrations compared to other congeners due to their relatively larger individual contributions to total PCB input.

Organochlorine pollutants pose a potential threat especially to human health and aquatic biota. PCBs were included in the dozen "dirty" POPs targeted by the Stockholm Convention. The maximum permissible levels of toxic organic pollutants for protection of human health and aquatic biota have been established in many countries. PCB levels in fish taken from Guanting Reservoir are very low when compared with the guideline value of $500 \mathrm{ng} / \mathrm{g}$ proposed by the National Academy of Sciences (USA) and with the $2000 \mathrm{ng} / \mathrm{g}$ of the Food and Drug Administration for total PCBs in fish muscle. It can be inferred from the present study that atmospheric deposition was probably a major source of PCB contamination in Guanting Reservoir and the levels of PCBs in fish are lower and they do not pose a risk to human health on the basis of existing related quality guidelines.

Acknowledgments. This research was supported by the National Natural Science Foundation of China (20437020) and KIP of CAS (RCEES 9902).

\section{REFERENCES}

ATSDR (2000) Toxicological profile for polychlorinated biphenyls (PCBs). US department of health and human services, public health service, Agency for Toxic Substances and Disease Registry, Atlanta, Georgia

Battershill JM (1994) Review of the safety assessment of PCBs with particular reference to reproductive toxicity. Human Exp Toxicol 13:581-597

Boon JP, Lewis WE, Tjoen-A-Choy MR, Allchin CR, Law RJ, De Boer J, Ten 
Hallers-Tjabbes CC, Zegers BN (2002) Levels of polybrominated diphenyl ether (PBDE) flame retardants in animals representing different trophic levels of the North Sea food web. Environ Sci Technol 36:4025-4032

Brouwer A, Ahlborg UG, Van den Berg M, Birnbaum LS, Boersma ER, et al (1995) Functional aspects of developmental toxicity of polyhalogenated aromatic hydrocarbons in experimental animals and human infants. European J Pharmacol 293:1-40

Capel PD, Rapaport RA, Eisenreich SJ, Looney BB (1985) PCBQ: Computerized quantification of total $\mathrm{PCB}$ and congeners in environmental samples. Chemosphere 14:439-450

Carpenter DO (1998) PCBs and human health. Int J Occup Environ Health 11:291-303

Duarte-Davidson R, Jones KC (1994) PCBs in the UK population: estimated intake, exposure and body burden. Sci Total Environ 151:131-152

Fisk AT, Hobson KA, Norstrom RJ (2001) Influence of chemical and biological factors on trophic transfer of persistent organic pollutants in the Northwater Polynya marine food web. Environ Sci Technol 35:732-738

Fowler SW (1990) Critical review of selected heavy metal and chlorinated hydrocarbon concentrations in the marine environment. Mar Environ Res 35:209-222

Fox K, Zauke GP, Butte W (1994) Kinetics of bioconcentration and clearance of 28 polychlorinated biphenyl congeners in zebrafish (Brachydanio rerio). Ecotoxicol Environ Saf 28:99-109

Frignani M, Bellucci LG, Carraro C, Russo A (2001) Distribution of polychlorinated biphenyls in dated sediments cores from the Venice Lagoon and the industrial area of Porto Marghera. Organohalogen Compd 51:65-68

Fürst P (1993) Contribution of different pathways to human exposure to PCDDs/PCDFs. Organohalog Compd 13:1-8

Kennish MJ (1997) Practical Handbook of Estuary and Marine Pollution. CRC Press, Boca Raton, FL

McFarland VA, Clarke JU (1989) Environmental occurrence, abundance and potential toxicity of polychlorinated biphenyl congeners: considerations for a congener-specific analysis. Environ Health Perspect 81:225-239

Montone RC, Taniguchi S, Weber RR (2001) Polychlorinated biphenyls in Marinr sediments of Admiralty Bay, King George Island, Antarctica. Mar Pollut Bull 42:611-614

Mormede S, Davies IM (2003) Horizontal and vertical distribution of organic contaminants in deep-sea fish specics. Chemosphere 50:563-574

Sun YZ, Wang X T, Xu XB (2005) Persistent Organochlorine Pesticide Residues in Fish from Guanting Reservoir, People's Republic of China. Bull Environ Contam Toxicol 74:537-544

Tanabe S, Iwata H, Tatsukawa R (1994) Global contamination by persistent organochlorine and their ecotoxicological impact on marine mammals. Sci Total Environ 154:163-177

Van den Berg, M. et al. (1998) Toxic equivalency factors (TEFs) for PCBs, PCDDs and PCDFs for humans and wildlife. Environ Health Perspect 106:775-792

Vit L (1992) Polychlorinated biphenyls in the environment. J Chromatog 595:1-43 